\title{
Versatile Ceramics
}

The ceramics industry has been active again this spring and early summer. Whether a new laboratory was inaugurated, capacities were expanded, a company anniversary was celebrated or an innovation prize was awarded - there were many events (see pages 6 to 11). A special highlight was the inauguration of a new field emission scanning electron microscope at the WesterWaldCampus, Höhr-Grenzhausen, Germany, see page 8. One of Europe's largest research and training centres for inorganic materials such as technical ceramics, glass and refractory materials is located there. The scientists are now in the process of setting up a microanalysis competence centre and significantly expanding their mineralogical-analytical competence.

But there were also interesting events and activities in other regions of the world. The X. International Conference on Refractory Materials, Furnaces and Thermal Insulations took place in Jasná (Low Tatras),
Slovakia. A detailed report on this topic can be found on page 12 and a technical article on refractory materials and their production can be found on page 22 .

Porous ceramics are another important topic (see page 16 and 30). These materials are becoming increasingly common in environmental and process engineering, for example in the case of substance separation, mixing and catalyst carriers. Their advantage over metallic materials is their high temperature and good corrosion resistance, especially against acids. In addition, they have very good abrasion resistance.

Furthermore, ceramics are increasingly being used in the field of biology and medicine, which is the subject of an article starting on page 36. Last but not least, there is an article about electro ceramics, which are indispensable materials for electrical engineering.

Thus, this issue once again shows how versatile ceramics can be. 